\title{
CAPACIDAD FECUNDANTE ESPERMÁTICA LUEGO DE LA RECUPERACIÓN DE ESPERMATOZOIDES MEDIANTE LA TÉCNICA DE SWIM-UP.
}

\author{
Beatriz Reina Bouvet', Cecilia Vicenta Paparella?, Rodolfo Nestor Feldman², Adriana María

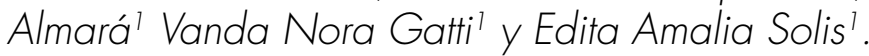

Departamento de Bioquímica Clínica', Facultad de Ciencias Bioquímicas y Farmacéuticas.

Servicio de Reproducción². Facultad de Ciencias Médicas. Universidad Nacional Rosario. República Argentina.

\begin{abstract}
Resumen.- OBJETIVO: Evaluar en pacientes infértiles, la calidad espermática pre y post swim up y compararla con una población de hombres fértiles.
\end{abstract}

MÉTODOS: De 55 pacientes que asistieron al Servicio de Reproducción del Hospital Centenario de Rosario a los que se efectuó espermograma y estudios funcionales espermáticos según normas OMS (1999), se seleccionaron 30 muestras de semen con volumen mayor de $1.0 \mathrm{ml}$, concentración de espermatozoides mayor de $5.000 .000 / \mathrm{ml}$ y que no presentaban hiperviscosidad. Se compararon los resultados obtenidos de: movilidad progresiva (MP), morfología (M), condensación de la cromatina (CC) e integridad de la cromatina (IC), en el semen fresco sin tratar (G2) y luego del swim-up (G3), con los valores obtenidos en muestras de semen fresco de 15 hombres fértiles $(G 1)$. Se utilizó microscopio óptico para estudiar la movilidad espermática progresiva, tinción Hematoxilina-Verde Brillante para analizar la morfología, azul de anilina para evaluar la condensación de la cromatina y el fluorocromo naranja de
Beatriz Reina Bouvet Gabriel Carrasco 1854 2000 Rosario. (Argentina) e-mail: beatrizbouvet@infovia.com.ar Trabajo recibido: 29 de marzo 2005 acridina para analizar la integridad de la cromatina. La técnica de recuperación espermática utilizada fue el swim-up, que se realizó en medio HTF, incubando en tubo Falcon a $45^{\circ}$ en estufa de $37^{\circ} \mathrm{C}$ gaseada (atmósfera de CO2 5\%) durante 1 hora. Luego se tomaron de la capa superior los espermatozoides que sobrenadaron, en los que se efectuaron las prácticas post swim-up. Se aplicó la prueba t- Student a los valores de los parámetros MP, M, CC e IC en los 3 grupos de pacientes, observándose diferencia significativa para los cuatro parámetros al comparar $G 1$ vs. G2 y $G 2$ vs. $G 3$ (p<0.001). No se encontró diferencia significativa al comparar G1 vs. G3 (p>0.11) lo cual indica que los parámetros estudiados MP, M, CC e IC, en los espermatozoides recuperados del swim-up, son semejantes a la población de hombres fértiles.

RESULTADOS: Estos resultados muestran que mediante swim-up se pueden recuperar gametas con capacidad fecundante potencial semejante a la población fértil, para aplicar en técnicas de reproducción asistida de baja complejidad, como la inseminación intrauterina, donde la selección natural es aún viable.

Palabras clave: Semen. Infertilidad. Capacidad fecundante. Espermatozoides. Cromatina. ADN.

Summary.- OBJECTIVES: To investigate sperm quality before and after swim up in infertile patients, and to compare it with a fertile men population.

METHODS: Semen samples from 55 patients consulting at the infertility services of the Hospitals "Centenario" in Rosario and "Eva Perón" in Gro Baigorria were collected and analyzed accordingly with the WHO guidelines. 30 sperm samples with a volume higher than $1.0 \mathrm{ml}$, and 
spermatozoid concentration higher than 5.000.000/ $\mathrm{ml}$, not presenting hyperviscosity were selected. Outcome variables including progressive mobility (PM), morphology (M), chromatin condensation (CC) and chromatin integrity $(\mathrm{Cl})$, were compared in fresh semen samples, between patients without previous treatment (G2) and after swim up (G3) and 15 fertile men (G1). Sperm morphology was evaluated by brilliant green hematoxyllin stain; progressive mobility with a subjective method accordingly to WHO (1999); chromatin condensation with aniline blue test; and chromatin integrity with acridine orange as fluorocrom. Swim up technique was based on Berger et al. (1985) with mHTF, heatingthe samples in a Falcon tube in a $45^{\circ}$ angle in a $37^{\circ} \mathrm{C}$ gas heater for one hour $15 \%$ CO2 atmosphere). Following incubation $0.5 \mathrm{ml}$ of the overlay containing sperm cells that swam up from the pellet were removed to process the recovered spermatozoids.

Student's t test was applied to compare PM, M, CC, and $\mathrm{Cl}$ between the four groups. A significant difference was found between $G 1$ vs $G 3$ and $G 2$ vs $G 3$ l $p<$ 0.0011 . No significant differences were found between $G 1$ and $G 3(p>0.1)$. It showed that PM, M, CC and $\mathrm{Cl}$ parameters in the recovered spermatozoids after swim up were similar to fertile population.

CONCLUSIONS: Our results indicate that through the swim up procedure gametes with fertile ability similar to normal fertile population can be recovered to be applied in low complexity in vitro fertilization techniques such as intrauterine insemination, where the natural selection is still viable.

Keywords: Sperm. Infertility. Fertilization ability. Spermatozoids. Chromatin. DNA.

\section{INTRODUCCIÓN}

Cuando se estudia la pareja infértil, el término "factor masculino" está ligado a una disminución de la capacidad fertilizante, debida a una o más anomalías seminales.

El semen humano exhibe una heterogeneidad muy grande o pleomorfismo, dentro y entre individuos.

Tradicionalmente al realizar el estudio del semen, se pone mayor énfasis en las determinaciones de movilidad y morfología espermática. No obstante, los resultados que proporcionan estos estudios rutinarios no proveen una información exacta de la capacidad fertilizante de las gametas.
Los espermatozoides son células complejas que están formadas por diferentes organelas y que desarrollan distintas funciones. Cada célula puede presentar su propia patología y es frecuente encontrar defectos asociados, lo que dificulta el estudio de alguna de las organelas con independencia de otras.

En pacientes infértiles se han descripto alteraciones en la morfología espermática, como vacuolas intracelulares, que aunque parecen ópticamente vacías poseen inclusiones pleomorfas, tales como grupos de membranas, vesículas de diferentes tamaños, gotas de lípidos, etc. Estas alteraciones se asocian con anormalidades en la condensación y la integridad de la cromatina nuclear del espermatozoide.

El porcentaje de espermatozoides eyaculados, con núcleo inmaduro puede ser predictivo de infertilidad masculina (1).

Así como la integridad y la funcionalidad de la membrana espermática son esenciales para la viabilidad, además de intervenir en los cambios fisiológicos necesarios para el proceso de fertilización (2), los defectos del núcleo espermático son de gran significación en fertilidad humana.

El ensayo de naranja de acridina mide la susceptibilidad del ADN a la desnaturalización ácida inducida por este colorante, cuantificándolo mediante el cambio metacromático de color verde (ADN nativo) al rojo (ADN desnaturalizado). Se postula que el ADN con estructura cromatínica anormal tiene una mayor susceptibilidad a desnaturalizarse. Por otro lado el colorante azul de anilina tiñe selectivamente proteínas ricas en lisina. Las histonas poseen esta propiedad, no así las protaminas. Por lo tanto, podemos utilizar esta tinción para evidenciar la presencia de histonas en núcleos espermáticos que no hayan realizado correctamente el proceso madurativo de intercambiar las histonas por protaminas. (3-4).

El hecho de que la infertilidad masculina puede ser tratada con técnicas de fertilización asistida (FIV), impulsó un rápido desarrollo de métodos que intentan predecir la funcionalidad espermática. y en los últimos años fueron incorporados a los laboratorios de andrología un número importante de esas determinaciones.

Actualmente existe una gran diversidad de alternativas de tratamientos para parejas infértiles, que presentan distinta complejidad, para lo cual se procesa el semen con el fin de "seleccionar" una cantidad adecuada de espermatozoides con capacidad potencial para fertilizar el ovocito, emulando la capacitación y selección que ocurre en el itinerario fisiológico en el tracto femenino. Los métodos más 
frecuentemente utilizados son: la técnica de sobrenado (swim-up) que describió Lopata en 1976 (5) y los gradientes de Percoll (swim-down), descripto por Foster en 1983 (6).

En la elección del método, según el tipo de semen y la técnica de fertilización que se va a emplear, se aplican criterios tales como: ser el menos traumático para los espermatozoides, con un procesamiento rápido y simple del semen que permita obtener espermatozoides con buena capacidad fecundante.

\section{OBJETIVO}

Nuestro objetivo fue estudiar, en pacientes infértiles, la calidad espermática pre y post swim-up y compararla con una población de hombres fértiles.

\section{MATERIAL Y MÉTODOS}

Se trabajó con 55 parejas que consultaron por infertilidad entre los meses de marzo y octubre del año 2002 en el Servicio de Reproducción del Hospital Provincial del Centenario Hospital Escuela de la Universidad Nacional de Rosario (Argentina). Luego de descartar el "factor femenino" como causa de infertilidad, fueron seleccionadas 30 muestras de semen con volumen seminal mayor de $1.0 \mathrm{ml}$, con concentración espermática mayor de $5.000 .000 / \mathrm{ml}$ y que no presentaban hiperviscosidad. Se efectuó espermograma y estudios funcionales espermáticos según normas OMS (7).

La movilidad progresiva de los espermatozoides $(a+b)$ se estudió con microscopio óptico y aumento de 400x. La morfología espermática se evaluó con la tinción Hematoxilina-Verde Brillante. La condensación de la cromatina se analizó con azul de anilina, colorante que se fija a las proteínas ricas en lisina, la presencia de espermatozoides morfológicamente normales cuyos núcleos están parcial o totalmente teñidos indican alteración en la condensación de la cromatina. La integridad de la cromatina se estudió con el fluorocromo naranja de acridina que emite fluorescencia roja cuando el ADN se encuentra desnaturalizado y verde cuando el ADN está en estado nativo.

La técnica de sobrenado (swim-up) se realizó en medio HTF (Irvine Scientific USA), incubando a $37^{\circ} \mathrm{C}$, los espermatozoides lavados en tubo Falcon, a $45^{\circ}$ en estufa gaseada latmósfera de $\mathrm{CO} 2$ $5 \%$ ) durante 1 hora, luego se recuperaron de la capa superior los espermatozoides que sobrenadaron y se repitieron las prácticas en las muestras post-swim-up.

Movilidad progresiva: Método subjetivo (7) Luego de la licuefacción de la muestra y antes de la hora de recolección se estudia la movilidad progresiva con microscopio óptico y $400 x$ de aumento, contando como mínimo 200 espermatozoides y clasificándolos según el tipo de movilidad.

Morfología espermática - Tinción Hematoxilina - Verde Brillante (8)

Reactivos: Hematoxilina de Harris $30 \%$ en solución acuosa. Metanol puro como fijador - Verde Brillante $0.1 \%$ en metanol.

Procedimiento: En portaobjetos desengrasados, se realiza un extendido con 10 ul de semen fresco, se deja secar al aire, luego se fija con metanol durante 3 minutos, se lava con agua y se seca al aire. Se cubre el extendido con Solución de Hematoxilina de Harris, se deja actuar 15 minutos, se lava con agua suavemente y por inmersión, se deja secar. Se cubre con Solución Verde Brillante y se deja actuar 5 minutos exactos. Se enjuaga con agua, se deja secar y se observa al microscopio con objetivo de inmersión de 1000x. Se cuenta como mínimo 200 espermatozoides clasificándolos según sus características morfológicas. Cuando hay más del 15\% de espermatozoides normales, se considera que el semen presenta morfología normal (7).

Condensación de la Cromatina - Test de Azul de Anilina (9)

Reactivo: azul de anilina (Cl 9655 Sigma ) 5\% P/V en ácido acético, pH: 3.5.

Procedimiento: Se lava una vez los espermatozoides con buffer fosfato salino (PBS). Se resuspende el pellet con 25 ul, 50 ul o 100 ul de PBS de acuerdo con la concentración de espermatozoides. Se hace un extendido con 10 ul de la suspensión de espermatozoides, se fija con metanol durante 10 minutos. Se enjuaga con agua destilada y se deja secar a temperatura ambiente. Se agrega el colorante azul de anilina y se deja actuar 3 minutos exactos. Se lava inmediatamente con agua. Se deja secar al aire y se mira al microscopio óptico con objetivo de inmersión (1000x). Se estudian 200 espermatozoides como mínimo, discriminando entre espermatozoides maduros no coloreados y espermatozoides inmaduros parcial o totalmente teñidos de azul. El resultado se expresa en porcentajes de ambos. 


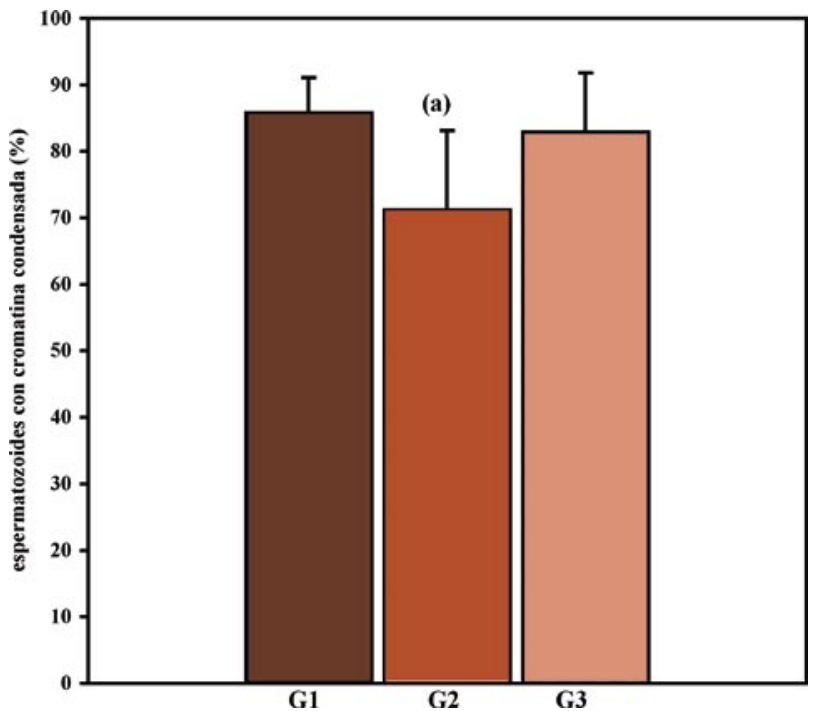

(a) $p<0,001$ vs. $G 1$ y $G 3$.

Interpretación: Solo tienen una buena condensación de la cromatina los espermatozoides que no se presentan coloreados.

Valores de referencia: mayor de $70 \%$ de espermatozoides maduros no coloreados.

Integridad de la cromatina - Test de naranja de acridina (3).

Reactivos: naranja de acridina (Cl 46005 Sigma) al $1 \%$ en PBS.

FIGURA 3.

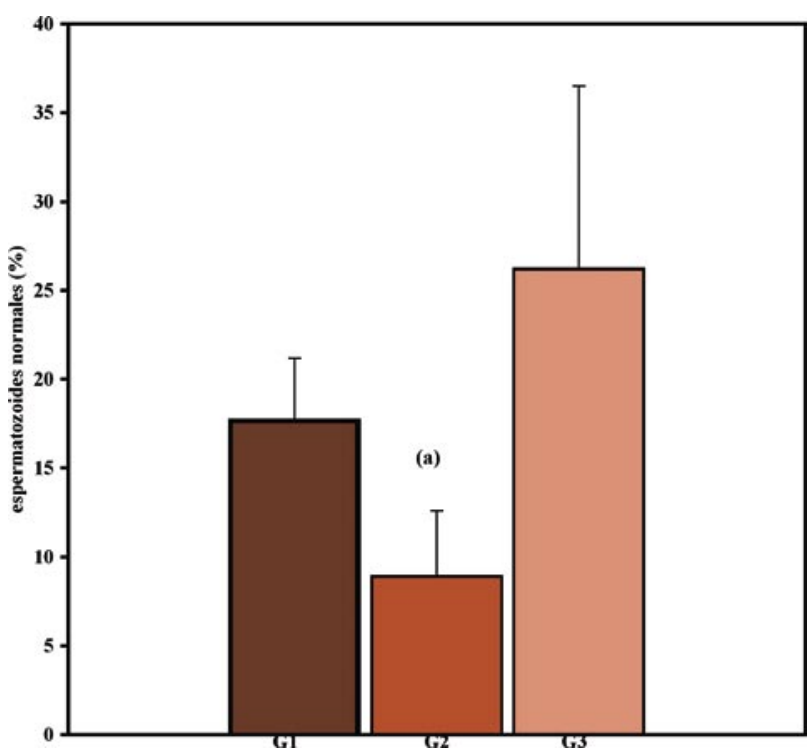

(a) $p<0,001$ vs. $G 1$ y $G 3$.

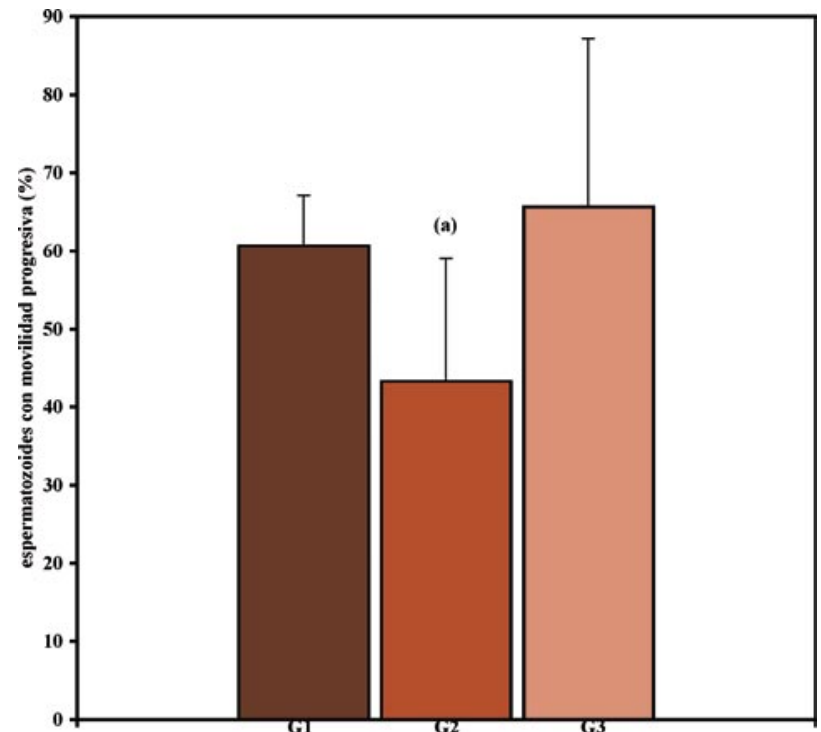

(a) $p<0,001$ vs. G1 y $G 3$.

Procedimiento: Se colocan 10 ul de semen fresco (sin tratamiento previo) y 10 ul de solución de naranja de acridina entre porta y cubreobjetos. Se incuba 5 minutos en cámara húmeda y se observa con microscopio de fluorescencia (400x). Las cabezas de los espermatozoides con $A D N$ en estado nativo emiten fluorescencia verde mientras que aquellos cuyo ADN se encuentra desnaturalizado se observan de color rojo. En donantes fértiles el test de naranja de acridina presenta mas de $50 \%$ de espermatozoides con ADN nativo y este porcentaje se toma como valor de referencia.

\section{FIGURA 4}

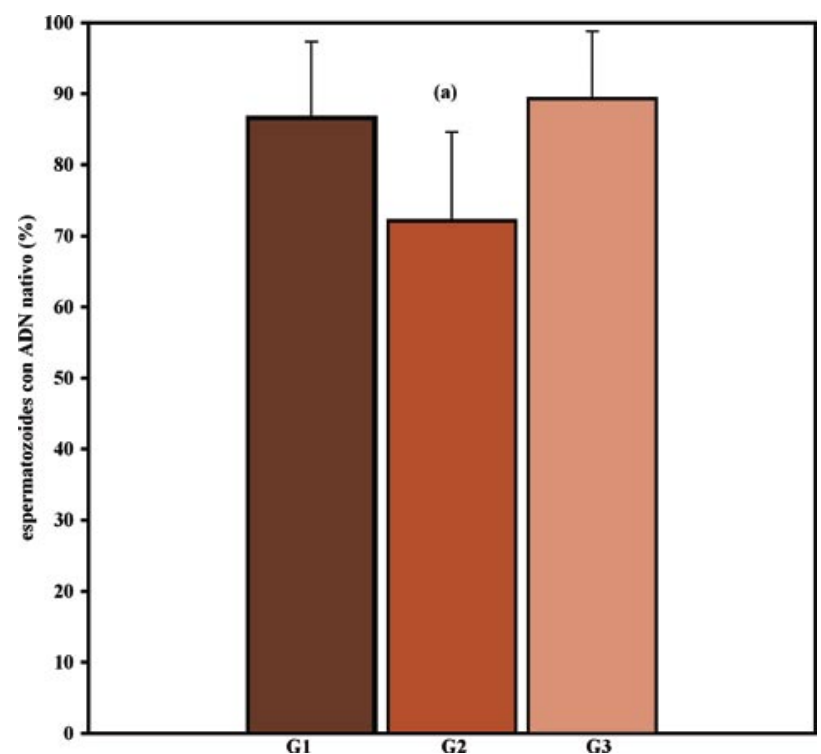

(a) $p<0,001$ vs. G1 y $G 3$. 


\section{Recuperación de espermatozoides - Técnica de so- brenado swim-up (10)}

Reactivos: medio HTF (Irvine Scientific USA) pH: 7.357.40

Procedimiento: en tubo Falcon se colocan $0.5 \mathrm{ml}$ de semen fresco y $3 \mathrm{ml}$ de medio HTF. Se homogeniza suavemente, se centrifuga a $300 \mathrm{~g}$ durante 10 minutos. Se remueve totalmente el sobrenadante por aspiración. Sobre el pellet, con el tubo Falcon inclinado a $45^{\circ}$ y utilizando pipeta Pasteur se agregan $0.5 \mathrm{ml}$ de medio HTF por las paredes y se lleva a estufa de $37{ }^{\circ} \mathrm{C}$ gaseada (en atmósfera de CO2 al 5\%) por 1 hora. Se toman del medio $0.4 \mathrm{ml}$ de la capa superior, que contiene los espermatozoides que sobrenadaron, y con ella se efectúan los estudios post swim-up de: $M P, M, C C$ e IC.

\section{RESULTADOS}

Los resultados de MP, M, CC e IC obtenidos para muestras de semen fresco pre swim-up (G2) y post swim-up (G3) de hombres infértiles se compararon con los valores encontrados en muestras de semen fresco provenientes de 15 hombres fértiles (G1).

Se encontraron diferencias significativas en los valores obtenidos para los cuatro parámetros, al comparar los grupos $G 1$ vs. $G 2$ y $G 2$ vs. G3 $(p<0.001)$ (Ver Figuras 1, 2, 3 y 4$)$.

Sin embargo no se encontraron diferencias significativas en ninguno de los parámetros estudiados al comparar G3 vs. G1 (p>0.1), lo que indicaría que las características de los espermatozoides recuperados luego del swim-up son similares a las de la población de hombres fértiles.

\section{DISCUSIÓN}

En contraste con otras especies animales el semen humano es único, por la cantidad de formas anormales que presenta el eyaculado. Es por ello que uno de los temas más controvertidos al estudiar una muestra seminal sea su morfología (8).

En casos de astenospermias severas, puede existir una alteración de la estructura del flagelo lo cual puede ser el origen de la deficiencia encontrada en un número apreciable de infertilidades masculinas (11).

La teratozoospermia es un factor importante de infertilidad humana y se pueden identificar como causas principales: la gran variedad de anomalías de las diferentes organelas de la gameta y el patrón homogéneo con un defecto sistemático presente en la mayoría de los espermatozoides.(12)

Los métodos de recuperación de espermatozoides, permiten seleccionar las gametas con mayor poder fecundante potencial y concentrar los espermatozoides con mayor aptitud para fecundar los ovocitos. El Percoll, si bien permite recuperar muestras con mayor densidad espermática, es una solución coloidal de partículas de sílice revestidas en polivinilpirrolidona, por lo cual no es inerte y puede desencadenar una reacción inflamatoria si no se elimina por completo de la suspensión espermática, antes de la inseminación intrauterina. Podría utilizarse para "rescatar" muestras de semen de mala calidad, no aptas para el swim-up.

El swim-up evita la exposición de células humanas a reactivos cuyos efectos a largo plazo no son conocidos permitiendo recuperar del semen los espermatozoides con características traslativas y estructurales de mejor calidad. Además constituye un método de aplicación en técnicas de reproducción asistida de baja complejidad, como la Inseminación Intrauterina, donde la selección natural del espermatozoide que fertilizará el ovocito es aún viable.

De acuerdo a nuestros resultados el swim-up podría ser el método de elección para el tratamiento de la infertilidad masculina en estos casos porque es sencillo, posee bajo costo y permite recuperar espermatozoides con capacidad fecundante potencial semejante a la de la población de hombres fértiles.

\section{BIBLIOGRAFÍA Y LECTURAS RECOMENDADAS (*lectura de interés $y^{* *}$ lectura fundamental)}

*1. CALAMERA, J.C.; NODAR, F.; ACOSTA, A.A.: "Papel de los tests de la función espermática". Secc. Art. Orig o de Rev., 2: 84, 1999.

**2. BOUVET, B.B.; BRUFMAN, A.S.; PAPARELLA, C.V. y cols.: "Estrés espermático modificado. Respuesta inmune y funcionalidad de la membrana del espermatozoide humano". Arch. Esp. Urol., 57, 2004.

*3. TEJADA, R.I.; MITCHELL, J.C.; NORMAN, A. y cols.: "A test for the practical evaluation of male infertility by acridine orange fluorescence". Fertil. Steril., 42: 87, 1984. 
4. GOPALKRISHNAN, K.; HURKDLI, K.; PADWAL, y cols.: "Use of acridine orange to evaluate chromatin integrity of human spermatozoa in different groups of infertile men". Andrología, 31: 277, 1999.

*5. LOPATA, J. y cols.: "Amethod for collection motile spermatozoa from human semen". Fertil. Steril., 27: 677, 1976.

6. FOSTER, M.S.; SMITH, W.D.; LEE, W.I. y cols.: "Selection of human spermatozoa accordding to their relative motility and their interaction with zona free-hamster eggs". Fertil. Steril., 40: 655, 1983.

**7. WHO.: "Laboratory manual for the examination of human semen and sperm-cervical mucus interaction". Fourth edition .Cambridge University Press. UK. 1999.

*8. CALAMERA, J.C.: "Morfología espermática para todos". Ediciones científicas Dr. José Montes (ed). Montevideo Uruguay. 1999.

9. DADOUNE, J.P.; MAYAUX, M.J.; GUILDHARD-MOSCATO.: "Correlation between defects of chromatin condensation of human spermatozoa stained by aniline blue and semen characteristics". Andrología, 20: 211, 1988.

*10. BERGER, T.; MARRS, R.P.; MOYER, D.L.: "Comparison of techniques for selection of motile spermatozoa". Fertil. Steril., 43: 268, 1985.

11. CHEMES, H.E.; BRUGO-OLMEDO, S.; CARRERE, C. y cols.: "Ultrastructural pathology of the sperm flagellum. Association between flagellar pathology and fertility prognosis in severely asthenozoospermic men”. Hum. Reprod., 13: 2521, 1.999.

12. KRUGER, T.F.; DU TOIT, T.C.; FRANKEN, D.R. y cols.: "Sperm mophology: assesing the agrement between the manual method (strict criteria) and the sperm mophology analyzer IVOS". Fertil. Steril., 63: 134, 1995. 